\title{
Radiocatalytic degradation of dissolved organic compounds in wastewater
}

Jaime Jiménez-Becerril,
Anabel Moreno-López,
Melania Jiménez-Reyes

\begin{abstract}
Wastewater containing a high concentration of organic substances was exposed to gamma radiolysis in the presence and absence of a catalyst $\left(\mathrm{TiO}_{2}\right)$; radiolysis and radiocatalysis were performed by means of continuous and discontinuous irradiation. Dissolved organic carbon (DOC) was the parameter used to estimate the concentration of organic compounds without interference by the high mineral content. The data was well fitted to the pseudo-first-order kinetic model of Langmuir-Hinshelwood. From a [DOC] $]_{0}=140 \pm 7 \mathrm{mg} / \mathrm{L}$, the higher DOC degradation (74\%) and apparent rate constant $\left(\mathrm{K}_{\mathrm{app}}=0.083 \mathrm{~h}^{-1}\right)$ were found using discontinuous radiocatalysis. This process could be an alternative method of treatment of industrial or municipal wastewater.
\end{abstract}

Key words: wastewater $\bullet$ dissolved organic carbon $\bullet$ radiocatalysis

J. Jiménez-Becerril ${ }^{\bowtie}$, A. Moreno-López,

M. Jiménez-Reyes

Departamento de Química,

Instituto Nacional de Investigaciones Nucleares,

Apartado Postal 18-1027 México, D.F. 11801 México,

E-mail: jaime.jimenez@inin.gob.mx

Received: 25 May 2015

Accepted: 25 August 2016

\section{Introduction}

A wastewater treatment plant may receive various types of wastewater - urban, industrial, and agricultural - containing all categories of pollutants, including persistent organic pollutants (POP), polycyclic aromatic hydrocarbons (PAH), and dissolved organic compounds (DOC). In addition to their potential toxicity, these organic compounds cause problems regarding the water's colour, smell, and taste. They are usually eliminated in wastewater plants through biological treatment; however, high concentrations remain in persistent and recalcitrant forms because they are non-biodegradable. Moreover, they sometimes inhibit the biodegradation processes, since some microorganisms are sensitive to them. Other waste disposal methods involve absorbent materials.

Advanced oxidation processes (AOPs) are based on physicochemical reactions that can bring profound changes to the chemical structure of the contaminants. They generate and use powerful transitional species, especially the hydroxyl radical $\left(\mathrm{HO}^{\circ}\right)$, which presents high effectiveness in oxidizing organic material because it reacts with contaminants and transforms them into compounds harmless to the environment [1]. These reactions can be generated by exposure to some forms of energy, such as UV light, and the processes can be improved with the presence of chemical oxidants [2]. AOPs 


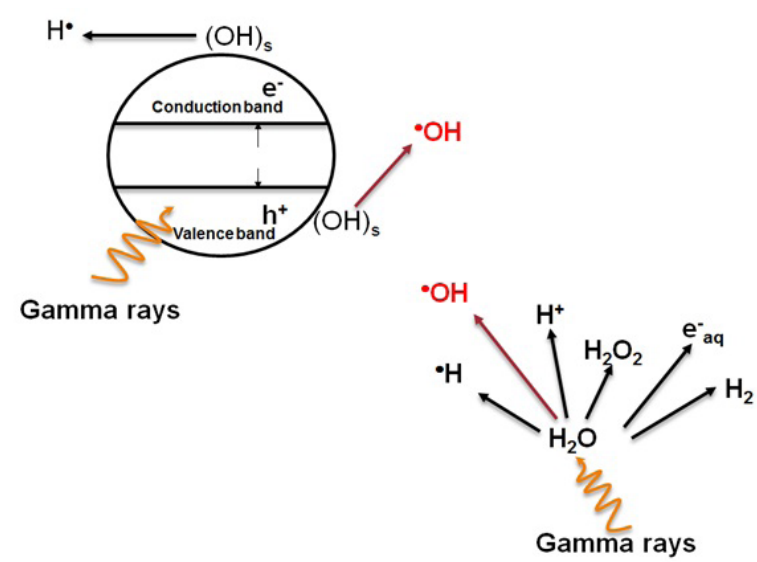

Fig. 1. Effect of gamma radiation on water-suspended particles and radical formation.

can be used alone, combined among themselves, or combined with conventional methods, and can be applied to air and soil pollutants [3]. Photocatalysis is an effective method that uses ultraviolet and visible radiation, as well as semiconductors such as $\mathrm{TiO}_{2}$, for the treatment of wastewaters in the environment [1-3].

On the other hand, gamma radiation technology is also used in environmental applications, mainly to eliminate the organic compounds present in wastewaters (see Refs. [4-6]). The radiolysis of water due to ionizing radiation results in the production of electrons, $\mathrm{H}^{\cdot}$ atoms, ${ }^{\circ} \mathrm{OH}$ radicals, $\mathrm{H}_{3} \mathrm{O}^{+}$ions, and molecules (hydrogen $\mathrm{H}_{2}$ and hydrogen peroxide $\mathrm{H}_{2} \mathrm{O}_{2}$ ). Gamma radiation technology is an AOP related to the use of the radical $\mathrm{HO}^{\circ}$ as a primary oxidant; radicals may be generated by ${ }^{60} \mathrm{Co}$ gamma radiation (Fig. 1), with the presence or absence of oxides such as $\mathrm{TiO}_{2}, \mathrm{Al}_{2} \mathrm{O}_{3}$, and $\mathrm{SiO}_{2}$, and the generation of reactive species gives rise to the oxidation-reduction of organic compounds. Gamma radiation also interacts with the oxides and causes electronic excitations, which promote an electron from the valence band to the conduction band, leaving a hole in the first band and resulting in a catalytic effect. These processes are used in the treatment of volatile organic compounds, such as dichloromethane, chloroform, phenols, and pesticides, [7-9]. Radiocatalysis is conceptually similar to photocatalysis.

Because some categories of pollutants contain hundreds of congeners, it is impractical to determine the concentration of each. Therefore, several methods have been developed to evaluate contaminants such as organic compounds in wastewaters. Among them are biological oxygen demand (BOD), chemical oxygen demand (COD), total demand of oxygen (TDO), and total organic carbon (TOC) methods. Total carbon is the sum of inorganic and organic [10]. Specific UV absorbance (SUVA) is the UV absorbance of a water sample at a given wavelength, normalized for dissolved organic carbon (DOC) concentration. The SUVA, determined at $254 \mathrm{~nm}$, is strongly correlated with the percentage of aromaticity [11]. Low concentrations of DOC generally indicate a high fraction of hydrophilic non-humic matter with low UV absorbance, a low chlorine demand, and low trihalomethane (THM) concentration. Medium DOC values are indicative of a mixture of hydrophobic humic and hydrophilic non-humic matter, with medium UV absorbance having a higher chlorine demand and higher THM concentration. High values of DOC are indicative of the presence of humic highly aromatic hydrophobic matter associated with high UV absorbance, high chlorine demand, and a high THM concentration [11]. DOC involves suspended organic carbon that is either purgeable or volatile and non-purgeable organic carbon. In this project, the amount of organic pollutants was measured through DOC determinations of wastewater previously microfiltered.

The purpose of the present research was to explore the application of radiolysis and radiocatalysis (both continuous and discontinuous) for organic compound degradation from industrial wastewater.

\section{Experimental}

Samples were collected at the wastewater treatment plant of the industrial corridor Toluca-Lerma (RECICLAGUA), located at Lerma, Estado de Mexico.

\section{Radiolysis and radiocatalysis}

The samples were exposed to gamma radiation using a Transelektro irradiator LGI-01 (manufactured by IZOTOP Institute of Isotopes Co. Ltd., Budapest, Hungary), which is provided with a ${ }^{60} \mathrm{Co}$ source (gamma ray energies: 1.17 and $1.33 \mathrm{MeV}$ ). The experiments took place in the National Institute of Nuclear Research (ININ). The delivered doses were in the range of $10-80 \mathrm{kGy}$ at a dose rate of $4.8 \mathrm{kGy} \cdot \mathrm{h}^{-1}$. The catalyst was $\mathrm{TiO}_{2}$ Degussa P25, which consisted of $75 \%$ anatase and $25 \%$ rutile, with a specific BET surface area of $50 \mathrm{~m}^{2} \cdot \mathrm{g}^{-1}$ and a mean pore diameter of $20 \mathrm{~nm}$.

Samples of $20 \mathrm{~mL}$ of wastewater previously filtered through a membrane with $0.45-\mu \mathrm{m}$ pore diameter, with and without $\mathrm{TiO}_{2}$, were continuously irradiated at 10, 20,40 , and $80 \mathrm{kGy}$. Other series of experiments were discontinuously irradiated as follows: the samples were irradiated at $20 \mathrm{kGy}$, the irradiation was interrupted for 3 minutes, and then the samples were again irradiated at $20 \mathrm{kGy}$ up to the final doses of 40 and $80 \mathrm{kGy}$. All experiments were done in duplicate.

The measurements via UV spectrophotometry were done immediately after irradiation. When $\mathrm{TiO}_{2}$ was present, the solutions were filtered through a membrane with $0.45 \mu \mathrm{m}$ pore diameter before measurements. A standard method [12] was used for the determination of UV absorption at $254 \mathrm{~nm}$ (UVA) in a spectrophotometer (PerkinElmer UV/VIS lambda 35, $1 \mathrm{~cm}$ quartz cell). Some experiments were measured again after one week.

The DOC in wastewater was measured by considering a calibration curve obtained with humic acid (sodium salt, Aldrich) solutions between 31 and $125 \mathrm{mg} \cdot \mathrm{L}^{-1}$, at $254 \mathrm{~nm}$. Organic carbon of 


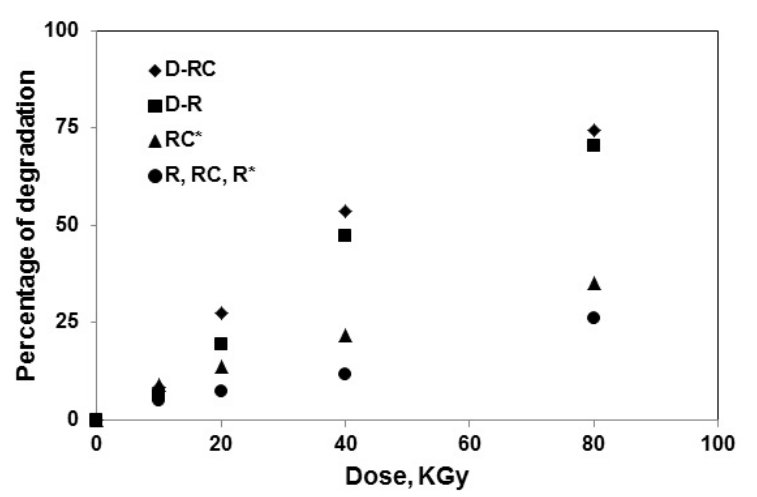

Fig. 2. Percentage of DOC degradation with respect to the adsorbed dose, D-RC: discontinuous radiocatalysis, D-R: discontinuous radiolysis, $\mathrm{RC}^{*}$ : radiocatalysis, measured after one week, $\mathrm{R}$ : radiolysis, $\mathrm{RC}$ : radiocatalysis, $\mathrm{R}^{*}$ : radiolysis, measured after one week.

this substance was reported as $(61 \pm 2) \%$ [13]; this value was considered for calculating the DOC in these solutions. The equation of the correlation line was: absorbance $=0.0311[\mathrm{DOC}], R^{2}=0.997$.

\section{Photolysis and photocatalysis}

To do a brief comparison, similar experiments were conducted by irradiating wastewater samples under UV radiation with stirring and a continuous supply of oxygen for 6,24 , and $30 \mathrm{~h}$. Before irradiations, the samples were stabilized in the dark for 35 minutes. Spectrophotometric measurements were done as described before, considering DOC as well.

\section{Results and discussion}

The filtered $(0.45 \mu \mathrm{m}$ pore diameter membrane) wastewater used in the study was transparent and brown; the degradation of the solutions was immediately observed by means of their discoloration. The $[D O C]_{\text {initial }}$ was $140 \pm 7 \mathrm{mg} / \mathrm{L}$.

The results of the different processes are given in Fig. 2. No sensible differences were observed for the measurements of radiolysis, radiocatalysis, and radiolysis, which were done immediately or one week after irradiation. However, for radiocatalysis solutions, a slight difference was observed, possibly reflecting a continued degradation. Discontinuous irradiations were even more effective than the other processes; under these conditions, $70 \%$ and $74 \%$ of

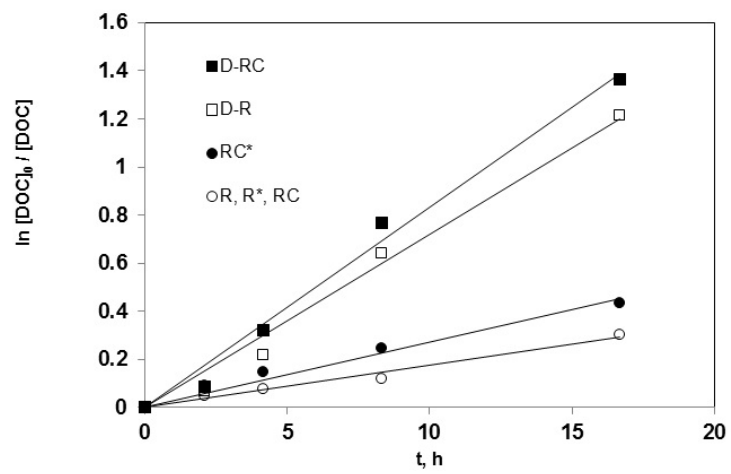

Fig. 3. Pseudo-first-order kinetic model of Langmuir-Hinshelwood D-RC: discontinuous radiocatalysis, D-R: discontinuous radiolysis, $\mathrm{RC}^{*}$ : radiocatalysis, measured after one week, $\mathrm{R}$ : radiolysis, $\mathrm{RC}$ : radiocatalysis, $\mathrm{R}^{*}$ : radiolysis, measured after one week.

the DOC were degraded after a total irradiation of $80 \mathrm{kGy}$, without and with the catalyst, respectively.

The data of continuous radiolysis and radiocatalysis measured one week after irradiation, as well as those from discontinuous radiolysis and radiocatalysis, were treated according to the pseudo-first-order kinetic model of Langmuir-Hinshelwood (Fig. 3), according to the following equation:

$$
\ln \frac{C_{0}}{C}=\mathrm{K}_{\text {app }} \cdot t
$$

where $C_{0}$ and $C$ correspond to initial concentration of DOC and to the concentration at time $t$, respectively; $K_{\text {app }}$ to the apparent rate constant of the process; and $t$ to the exposition time. The obtained parameters are given in Table 1.

According to the data given in Table 1, the apparent rate constant of the Langmuir-Hinshelwood model and $t_{1 / 2}$ have virtually the same value for continuous radiolysis and radiocatalysis; and a slight enhancement is observed for the radiocatalytic process measured one week later. On the contrary, the discontinuous processes notoriously enhanced the degradation of DOC, especially in the presence of $\mathrm{TiO}_{2}$.

There is no recommended value for DOC in our country, but to extrapolate up to the limit value of DOC for recharge wastewater $\left(\leq 1 \mathrm{mg} \cdot \mathrm{L}^{-1}\right)$ [14], the equations of the lines $\left([\mathrm{DOC}]=m^{*}\right.$ (Dose, $\left.\mathrm{kGy}\right)+$ $b$ ) were considered. The results are given in Table 1; a discontinuous dose $\geq 100 \mathrm{kGy}$ would be enough to attain $\leq 1 \mathrm{mg} \cdot \mathrm{L}^{-1}$.

It is not easy to explain the behaviour of discontinuous irradiations; however, the experiments of

Table 1. Maximal percentages of DOC degradation (at $80 \mathrm{kGy}$ ), apparent rate constant of the Langmuir-Hinshelwood model, correlation constant of the equation of this model, and mean time. *: Measurements made after one week. $D$ : minimal dose calculated for attained $[\mathrm{DOC}] \leq 1 \mathrm{mg} / \mathrm{g}$

\begin{tabular}{lccccc}
\hline \multicolumn{1}{c}{ Processes } & $\begin{array}{c}\text { DOC degradation } \\
{[\%]}\end{array}$ & $\begin{array}{c}\mathrm{K}_{\mathrm{app}} \\
{\left[\mathrm{h}^{-1}\right]}\end{array}$ & $R^{2}$ & $\begin{array}{c}t_{1 / 2} \\
{[\mathrm{~h}]}\end{array}$ & $\begin{array}{c}D \\
{[\mathrm{kGy}]}\end{array}$ \\
\hline Radiolysis & 26 & 0.016 & 0.95 & 3.2 & 321 \\
Radiocatalysis & 26 & 0.019 & 0.98 & 3.1 & 309 \\
Radiolysis* & 26 & 0.017 & 0.96 & 3.2 & 322 \\
Radiocatalysis* & 35 & 0.027 & 0.97 & 2.2 & 231 \\
Discontinuous radiolysis & 70 & 0.072 & 0.98 & 0.7 & 107 \\
Discontinuous radiocatalysis & 74 & 0.083 & 0.99 & 0.6 & 100 \\
\hline
\end{tabular}


radiocatalyst measured one week after irradiation showed that degradation of DOC continues at the end of irradiation. Therefore, each new dose of gamma radiation may increase the quantity of $\mathrm{OH}$ radicals that enhance DOC degradation.

Regarding the results of the UV irradiations, practically no degradation $(99 \pm 1 \%)$ of DOC was obtained due to photolysis (up to $30 \mathrm{~h}$ of exposition) nor from photocatalysis after up to $24 \mathrm{~h}$ of irradiation. Only with $30 \mathrm{~h}$ of photocatalysis was a $35 \%$ of degradation observed; this value is similar to that obtained with $16.6 \mathrm{~h}$ of radiocatalysis $(80 \mathrm{kGy}$ and measurements done one week after).

\section{Conclusions}

All the radiolysis conditions studied were capable of degrading DOC, whereas with photocatalysis, the DOC degradation was only observed after $30 \mathrm{~h}$ of exposition. Discontinuous processes enhanced the degradation of DOC, especially in the presence of $\mathrm{TiO}_{2}$. The percentage of DOC removed from the wastewater, the apparent rate constant of the Langmuir-Hinshelwood model, the mean time, and the calculated dose for [DOC] $\leq 1 \mathrm{mg} / \mathrm{L}$ for the discontinuous radiolysis and radiocatalysis indicate that both processes have similar behaviour in these conditions. They are more efficient for the degradation of organic compounds than the other processes studied.

Acknowledgments. A. Moreno-López thanks the Instituto Nacional de Investigaciones Nucleares (Mexico) for her bachelor's scholar grant.

\section{References}

1. Ribeiro, A. R., Nunes, O. C., Pereira, M. F. R., \& Silva, A. M. T. (2015). An overview on the advanced oxidation processes applied for the treatment of water pollutants defined in the recently launched Directive 2013/39/EU. Environ. Int., 75, 33-51. DOI: 10.1016/j.envint.2014.10.027.

2. Luo, Y., Guo, W., Ngo, H. H., Nghiem, L. D., Hai, F. I., Zhang, J., Liang, S., \& Wang, X. C. (2014). A review on the occurrence of micropollutants in the aquatic environment and their fate and removal during wastewater treatment. Sci. Total Environ., 473/474, 619-641. DOI: 10.1016/j.scitotenv.2013.12.065.

3. Matilainen, A., \& Sillanpää, M. (2010). Removal of natural organic matter from drinking water by advanced oxidation processes. Chemosphere, 80 , 351-365. DOI: 10.1016/j.chemosphere.2010.04.067.

4. Bao, H., Liu, Y., \& Jia, H. (2002). A study of irradiation in the treatment of wastewater. Radiat. Phys. Chem., 63, 633-636. DOI: 10.1016/S0969806X(01)00619-3.

5. Kimura, A., Taguchi, M., Ohtani, Y., Shimada, Y., Hiratsuka, H., \& Kojima, T. (2007). Treatment of wastewater having estrogen activity by ionizing radiation. Radiat. Phys. Chem., 76, 699-706. DOI: 10.1016/j.radphyschem.2006.04.005.

6. Chmielewski, A. G., \& Haji-Saeid, M. (2004). Radiation technologies: past, present and future. Radiat. Phys. Chem., 71, 17-21. DOI: 10.1016/j.radphyschem.2004.05.040.

7. González-Juárez, J. C., Jiménez-Becerril, J., \& CejudoÁlvarez, J. (2010). Degradation of 4-chlorophenol by gamma radiation of ${ }^{137} \mathrm{Cs}$ and X-rays. J. Mex. Chem. Soc., 54, 157-159. Available from http://www.scielo. org. $\mathrm{mx} /$ scielo.php? script $=$ sci_arttext $\&$ pid $=\mathrm{S} 1870$ 249X2010000300005\&lng $=\mathrm{e} \overline{\mathrm{n}}$.

8. Velo-Gala, I., López-Peñalver, J. J., Sánchez-Polo, M., \& Rivera-Utrilla, J. (2014). Role of activated carbon on micropollutans degradation by ionizing radiation. Carbon, 67, 288-299. DOI: 10.1016/j. carbon.2013.09.091.

9. Abdel daiem, M. M., Rivera-Utrilla, J., Ocampo-Pérez, R., Sánchez-Polo, M., \& López-Peñalver, J. J. (2013). Treatment of water contaminated with diphenolic acid by gamma radiation in the presence of different compounds. Chem. Eng. J., 219, 371-379. DOI: 10.1016/j.cej.2012.12.069.

10. American Public Health Association. (2005). Standard methods for the examination of water and wastewater (21st ed.). Washington: APHA.

11. Weishaar, J. L., Aiken, G. R., Bergamaschi, B. A., Fram, M. S., Fujii, R., \& Mopper, K. (2003). Evaluation of specific ultraviolet absorbance as an indicator of the chemical composition and reactivity of dissolved organic carbon. Environ. Sci. Technol., 37, 4702-4708. DOI: 10.1021/es030360x.

12. Potter, B. B., \& Wimsatt, J. C. (2005, February). Determination of total organic carbon and specific UV absorbance at $254 \mathrm{~nm}$ in source water and drinking water. Revision 1.1. Method 415.3. Cincinnati: US EPA. (EPA/600/R-05/055).

13. Jiménez-Reyes, M., \& Solache-Ríos, M. (2012). The influence of $\mathrm{pH}$ on the stability constants of lanthanum and europium complexes with humic acids. J. Radioanal. Nucl. Chem., 293, 273-278. DOI: 10.1007/s10967-012-1730-1.

14. Secretaría del Medio Ambiente y Recursos Naturales, Comisión Nacional del Agua Norma Oficial Mexicana. (2009, 18 August). NOM-014-CONAGUA-2003, Requisitos para la recarga artificial de acuíferos con agua residual tratada. Diario Oficial de la Federación. Received 2015, from http://dof.gob.mx/nota detalle. php? codigo $=5105753 \&$ fecha $=18 / 08 / 2009$ 